\title{
DIGITAL COMPETENCES AND SOCIAL IMPACT: EXTRACURRICULAR LEARNING
}

\author{
A. Freire, V. Moreno Oliver \\ Universitat Pompeu Fabra (SPAIN)
}

\begin{abstract}
The underrepresentation of women in technical degrees is a matter of concern, as it leads to multiple issues such as the lack of diversity and the exclusion of women from the tech industry and job market. Several initiatives have been developed to fight against this situation. Many of those target Primary School students, as gender stereotypes are developed during early years and they have been identified as one of the reasons why female students do not choose technical careers.

This work evaluates the cross-sectional impact of an extracurricular activity identified as the first one targeting a mixed audience, covering a wide age range, and with cross-border and multi-competence effect. This activity consists in an international contest, launched in Spain and Latin America, where groups of students meet female professionals working in technology, that act as role models breaking classical stereotypes. Students create a website including profiles of women in tech: their biography, career, main achievements, and any other aspects that the students want to include. Instead of promoting classical female role models, the contest forces participants to select contemporary professionals that live in their own country or even their city, so students can meet more close inspirational models. The contest evaluation criteria prioritize those websites containing video or text interviews with the professionals, encouraging the students to meet them and ask them all their questions and concerns.

Using questionnaires addressed to both teachers and students, we have studied the evolution of the impact of the activity during two editions. We have identified an increase in the cognitive and emotional impact, on both students and teachers. This initiative has managed to break gender stereotypes associated with technological professions, while promoting interest in technical careers, teamwork, digital skills, research capacity and creativity.
\end{abstract}

Keywords: Gender stereotypes, secondary education, digital culture, social impact, ICT competence/skill.

\section{INTRODUCTION}

Despite the ubiquitous presence of science and technology in society, women are still underrepresented in those sectors, as well as in engineering and maths (commonly grouped under the acronym STEM). In the Spanish University, in the academic course $2017-2018$, only $12.2 \%$ of the students of Computer Science were female. This percentage was a little higher but still low in the case of Industrial Engineering (28.4\%). In general, while the $55.1 \%$ of the university students are female, just the $49.2 \%$ choose a science degree [1].

However, technological disciplines, in particular, offer uncountable job opportunities, competitive salaries and productivity. The unemployment rate in this sector is so low that the European Union estimated that in the next years more than half a million jobs will remain unfilled due to the lack of qualified professionals. This trend is expected to continue growing with the rapid proliferation of technology. Therefore, there is an urgent need for society of facing this great opportunity offered by the labour market. However, if technology careers continue being mostly occupied by men, there will be an increasing trend towards: (1) exclusion of women from great job opportunities and (2) masculinization of the technology industry, with all the negative implications both for companies and their developments due to the lack of any type of diversity [2][3].

Consequently, urgent measures are needed to stimulate scientific-technological vocations in society. This implies addressing the cause of this lack of vocations. Both girls and boys are exposed to the influence of multiple social, cultural or economic factors, but various studies suggest that stereotypes associated with technical careers have a great influence on both genders from an early age [4][5]. These stereotypes can influence in various ways, among which we highlight the following: 
- Lack of inspiring female references and low visibility of profiles of women working in science and technology: the career paths that girls and boys imagine for their future from an early age determine their choices throughout the educational system, such as when they choose a high school specialization [6].

- Unconscious bias: present in relatives, teachers and colleagues (regardless of their gender). As a result, girls are indirectly offered fewer opportunities for these roles (studying STEM careers or even holding leadership positions) [8]. Unconscious bias develops at an early age [9], so actions are needed, not only for girls, to fight against these prejudices that can potentially affect their lives, but also to avoid perpetuating them at future generations. Recently, this issue claims attention from the research community, educators and politicians [7].

Currently, in Spain, there are several initiatives to promote technology among young girls, such as Technovation Challenge ${ }^{1}$, Girls Gonna ${ }^{2}$, Mujeres Tech ${ }^{3}$ or Inspira STEAM ${ }^{4}$, among others, but none of them are addressed to a mixed audience (girls and boys), with a wide age range and with an international and multicompetence scope. With this motivation, the project Wisibilizalas was launched in order to achieve the following objectives:

1 Breaking gender stereotypes associated with professions in technology.

2 Giving global visibility to the role of women in technology.

3 Promoting technology among non-university students (female and male) and their teachers.

4 Providing a scenario for active work on transversal skills such as teamwork, critical and selfcritical capacity, research capacity, creativity and innovation.

This project, launched in 2016, consists of an annual contest aimed at Spanish-speaking Primary and Secondary students. Each centre can participate with several gender-mixed teams of up to 10 students, led by a teacher. The teams design and implement a web page including profiles of women currently working in technology. They should include their biography, professional career, awards, and any other relevant information. We force to choose contemporary professionals in order to promote close profiles that the students can contact and even interview to maximize the impact on them. In order to encourage students to do research, we value that the profiles are not yet published on Wikipedia, so not only profiles of highly relevant women are accepted, but also professionals from their city or alumni from their school. The web must include multimedia content, such as images of the candidates or videos of the interviews; thus, students (and teachers) acquire skills for web development and also for multimedia edition.

A committee composed of volunteers from academia and industry evaluates the web sites based on different criteria, such as the number, quality and originality of the published profiles, the use of multimedia or the web design.

After finishing the contest, an evaluation is carried out among the participants to evaluate the impact and awareness from two different perspectives: the takeaways of the contest (breaking gender stereotypes and acquiring new technological knowledge) and the satisfaction of the participants (teachers and students). From this evaluation, we can define new challenges and conclusions.

\section{METHODOLOGY}

Wisibilízalas is an ambitious project with social, contextual, digital and technological impact. Due to the complexity of the analysis of these variables and considering the time it takes to see the causal effects of this type of initiatives, we established a bi-annual evaluation process. Every evaluation includes more variables than the previous one. For instance, the evaluation carried out in the first edition (2016-2017) [10] was just focused on objectives 1, 3 and 4. In the third edition (2018-2019), we also included questions specifically related to objective 2 . Thus, we continue building a historical record that allows us to show some trends at the same time we gather more relevant information from defining new variables. In this paper we evaluate the effect of the third edition, and we stablish comparisons with the results obtained in the first one.

\footnotetext{
${ }^{1}$ https://technovationchallenge.org/

${ }^{2}$ https://girlsgonna.com/

${ }^{3}$ https://mujerestech.com/

${ }^{4}$ https://inspirasteam.net/
} 
The methodology for evaluating the impact of the third edition is based on two questionnaires specifically designed for this purpose. Using the online tool "Google Forms", we designed two anonymous questionnaires addressed to teachers and students. The following sections detail the content of these instruments, the data and samples, as well as the qualitative assessments provided by the participants.

To facilitate the reading and understanding of the results, we present the evaluation of teachers and students separately. Finally, a joint analysis is presented, considering the global results, as well as a comparison with the results obtained in the first edition of the contest.

\subsection{Population and sample}

In the third edition of the contest, the population consisted of 568 subjects (30 teachers and 538 students). In the first edition, the population was composed of 115 subjects (10 teachers and 105 students). Thus, the participation increased by $394 \%$.

The participation is $63.33 \%$ in the case of teachers and $14.6 \%$ in the case of students (note that Primary school did not participate in the evaluation).

\subsection{Instruments for evaluation}

As we have stated before, two separate instruments were applied to differentiate the evaluation of teachers and students. However, the variables of interest of both instruments are shared in most cases. Also, we must note that we kept the items of the instrument applied in the evaluation of the first edition, in order to make comparisons with the third edition.

Both instruments collected personal information (age, gender and province), keeping the anonymity of the participants, as well as the motivation for participating in the contest (using a paragraph text field). Next, 7 statements were addressed to the teachers ( 8 to the students), where they had to indicate their degree of agreement using a scale from 1 to 4 (being 1 the minimum degree of agreement and 4 the maximum). These statements were related to the perception of impact of their participation in the contest regarding:

- Facilitation of critical reflection and awareness about women in technology among young people.

- Perception of support by the centre and colleagues regarding the participation in the contest.

- Assessment of the experience from both the teaching and student point of view and microdissemination.

- Perception and self-perception of the real impact on the attitude and knowledge of young people regarding the topic of women and science/technology.

- Dissemination of the contest among other centres and colleagues.

In the case of teachers, they were also asked about how difficult was to find female profiles in technology (using a scale from 1 to 4 , being 1 "very difficult" and 4 "very easy"). Also, they were asked if they had done any kind of specific training (formal or self-taught) for guiding the students during the development of the websites (web design, multimedia edition, etc.). Subsequently, there were two open fields in which teachers were asked to indicate, in terms of relevance, the highlights of the participation in the contest and the aspects of improvement for future editions.

In the case of students, we added three cross-sectional questions related to their perception of learning of technological competences: web design, video editing and professional profiles in technology. Participants had to indicate how much they had learned from each of them using a scale from 1 to 4 , being 1 "nothing" and 4 "a lot". Students were asked about the aspects that they liked the most and least about the contest.

In both cases, the questionnaire ended with a paragraph text field to allow participants to add other comments or suggestions. 


\section{RESULTS}

This section presents the results obtained in the evaluation of satisfaction and impact in the third edition of the context Wisibilizalas. Since these results come from different groups (teachers and students), they are presented in separate subsections.

\subsection{Teachers evaluation}

The $63.33 \%$ of the teachers participated in the evaluation process of the third edition. The average age of the teaching staff was 45 years versus 43 in the first edition. In terms of gender, the percentage of women is notably higher than that of men: $73.7 \%$ women and $26.3 \%$ men. This means a significant change with respect to the first edition, that was totally balanced. As the scope of the contest is international, we found interesting to report as well the distribution of the sample according to the region: Balearic Islands (5), Barcelona (3), Seville (3), A Coruña (2), Madrid (1), Lleida (1) , Valencia (1), Capital District (1), Quito (1) and Tabasco (1).

Regarding the motivation to participate in the contest, the teaching staff reflects elements shared with those collected in the first edition, especially those related to raising awareness and interest in making young people aware of the subject (women and technology) as well as the commitment of the teachers with the transversal competences related to gender, science, respect, etc. that compute practically $100 \%$ of the comments.

As specified above, in the evaluation of the third edition, a question on specific training was added to the questionnaire addressed to teachers. The item specifically read "Indicate if you have completed any type of specific training (formal or self-taught) in order to participate in the contest (web design, video editing, etc.)". Three possible answers were offered, including "formal", "self-taught training" and a last option "none", targeting those teachers who did not need any training since they already had the necessary knowledge. The distribution of the responses was as follows: 13 of the 19 participants $(68 \%)$ indicated that training was not necessary and the remaining 5 participants $(32 \%)$ indicated that they had to do training, but in a self-taught way. The motivation for adding this question was two-fold: (1) knowing the teachers' self-perception in terms of digital competences, to study if this could be a factor that could condition the participation in the contest; and (2) getting a global vision of the effort and implication that the teaching staff assumes to mentor the participating teams.

Table 1 shows the 7 statements related to the teachers' perception regarding the impact of participation in the contest at different levels. Remember that the scale to indicate the degree of agreement with the statements was from 1 to 4 , being 1 the minimum value of agreement and 4 the maximum. For each statement we report the mean, the standard deviation and the mode. Table 1 also reports the results obtained in the evaluation of the first edition (2016-17), highlighting the most recent one (2018-19).

The letters in the first column correspond to the following items:

A. I believe that actions such as this contest help young people to reflect on social issues such as the role of women in technology

B. I am glad that my school was involved in the contest

C. My colleagues from the centre have been concerned about how our participation in the contest was going

D. The centre has given visibility to our participation in the contest

E. I personally consider this a positive experience for both myself and the students

F. Since we participated in the contest, I have observed that there is a greater sensitivity and a more careful attitude regarding issues related to gender (visibility of women in masculinized environments, use of sexist language, stereotypes, etc.)

G. I would recommend participation in the contest to colleagues from other centres 
Table 1. Teacher assessment regarding the perceived impact.

\begin{tabular}{c|c|c|c|c|c|c}
\hline \multirow{2}{*}{} & \multicolumn{2}{|c|}{ Mean } & \multicolumn{2}{c|}{ Standard Deviation } & \multicolumn{2}{c}{ Mode } \\
\cline { 2 - 7 } & $\begin{array}{c}\text { Edition } \\
2016-17\end{array}$ & $\begin{array}{c}\text { Edition } \\
2018-19\end{array}$ & $\begin{array}{c}\text { Edition } \\
2016-17\end{array}$ & $\begin{array}{c}\text { Edition } \\
2018-19\end{array}$ & $\begin{array}{c}\text { Edition } \\
2016-17\end{array}$ & $\begin{array}{c}\text { Edition } \\
2018-19\end{array}$ \\
\hline $\mathrm{A}$ & 3.70 & 3.90 & 0.67 & 0.32 & 4 & 4 \\
\hline $\mathrm{B}$ & 3.80 & 3.90 & 0.42 & 0.32 & 4 & 4 \\
\hline $\mathrm{C}$ & 2.20 & 2.90 & 0.63 & 0.81 & 2 & 2 \\
\hline $\mathrm{D}$ & 2.80 & 3.30 & 0.92 & 0.65 & 3 & 3 \\
\hline $\mathrm{E}$ & 3.80 & 3.80 & 0.42 & 0.42 & 4 & 4 \\
\hline $\mathrm{F}$ & 3.10 & 2.90 & 0.74 & 0.88 & 3 & 3 \\
\hline $\mathrm{G}$ & 3.90 & 3.80 & 0.32 & 0.37 & 4 & 4 \\
\hline \hline
\end{tabular}

As you can see in Table 1, the mean of 6 out of 7 items is higher than in the first edition. In 5 items, the mean reaches 3 out of 4 points with clear homogeneity indicated by the standard deviation. We would like to highlight three of the listed items: A, B and D, all of them related to the social impact of the contest and the perception of the implication of the educational community. In these three items, the mean is higher, and the standard deviation is lower, meaning more robust and consistent results. The value of the mode also supports this fact. It is worth to mention that these marks in these particular items mean very good results, as these items refer to the impact of the contest, the implication of the centre and the dissemination and visibility of the participation of the centres in their close environment.

The items related to global satisfaction (item E) and recommendation to other centres (item $\mathrm{G}$ ) achieved the highest average score (3.8/4 and 3.9/4 respectively), and the lowest standard deviation (between 0.32 and 0.42 ) with a mode of 4 out of 4 points.

Next, regarding the perception of the teachers for finding female professionals in technology, the average score is $2.4 / 4$ (note that 1 means "very difficult" and 4 means "very easy") and the standard deviation is 0.84 , indicating a little dispersion in the answers of the teachers. However, the mode is 3 out of 4 .

We also include a compilation of comments written by the teachers in the questionnaires, in relation with the impact and relevance of the contest, as well as the elements to be improved. The frequency of each element is indicated between parenthesis.

- Elements related to impact and relevance:

- Implication, interest and compromise by the students (7)

- Awareness raised in relation to the topic of the contest (give visibility to female role models in technology) as well as the acquired knowledge (5)

- Teamwork (4)

- Teachers implication (3)

- Elements to be improved:

- Expanding the scope of the contest, so teams can also include profiles of female professionals in STEM, not only in technology (4)

- Extending the deadline of the contest, so the teams can have more time for developing the project (2)

- Facilitating the attendance to the awards ceremony, as it can be difficult for the centres to manage the trip to Barcelona (2)

- Making it easier to get the parents authorizations to allow the students their participation in the contest (2)

Teachers highlight elements related to the implication, interest and compromise of the students (item also reflected in the first edition of the contest). They also note the awareness with the topic and the importance of developing the project in groups. Teachers suggest expanding the scope of the contest to include professionals in technology but also in science, maths and engineering. 
Teachers wrote as well other general comments to thank the organisation for the initiative, that they describe as interesting, needed and of high impact not just for the students (micro level) but also for the educational community (general level). The content of these comments are reflected in the results analysed previously.

\subsection{Students evaluation}

The participation among the students was lower than in the case of the teachers. Just 44 students out of 538 filled the evaluation form, representing the $14.6 \%$ of the population (36.2\% in the first edition). The average age of the participant is 15 years old, as in the first edition. In terms of gender, the percentage of girls $(59 \%)$ is a bit higher than that of boys $(41 \%)$. This distribution is very similar to the one observed in the first edition (58\% female representation).

Regarding the motivation of the students to participate in the contest, we collected the following reasons:

- Intrinsic motivation and personal interest on the topic of the contest. (57\% of the responses)

- Inclusion of the contest as a curricular activity. Although the main motivation came from the teachers, they specify that most of the students participated with enthusiasm. $(29.5 \%$ of the responses)

- The remaining $13,5 \%$ do not clarify the motivation beyond curricular aspects, grades, etc.

Table 2 lists the 8 statements related to the impact perceived by the students regarding their participation in the contest. The degree of agreement was measured between 1 and 4 , being 1 the minimum value of agreement and 4 the maximum. We also report the mean, standard deviation and mode for the third edition and the first one. The letters in the first column correspond to the following items:

a) I believe that actions like this contest help young people to reflect on social issues such as the role of women in technology.

b) I am glad that my school was involved in the contest.

c) I have told my family and friends about the contest.

d) Before participating, I would not have been able to identify 3 female professionals in technology.

e) Now I am able to identify at least 3 women of reference in the field of science and technology.

f) After the contest, I feel more sensitive and careful about gender-related issues (visibility of women in masculinized environments, use of sexist language, stereotypes, etc.).

g) Since we participated in the contest I have noticed (small) changes in attitude in my classmates and teachers regarding gender issues (visibility of women in masculinized environments, use of sexist language, stereotypes, etc.).

h) I would recommend my friends the participation in the contest.

Table 2. Student assessment regarding the perceived impact.

\begin{tabular}{c|c|c|c|c|c|c}
\hline \hline \multirow{2}{*}{} & \multicolumn{2}{|c|}{ Mean } & \multicolumn{2}{c|}{ Standard Deviation } & \multicolumn{2}{c}{ Mode } \\
\cline { 2 - 7 } & $\begin{array}{c}\text { Edition } \\
2016-17\end{array}$ & $\begin{array}{c}\text { Edition } \\
2018-19\end{array}$ & $\begin{array}{c}\text { Edition } \\
2016-17\end{array}$ & $\begin{array}{c}\text { Edition } \\
2018-19\end{array}$ & $\begin{array}{c}\text { Edition } \\
2016-17\end{array}$ & $\begin{array}{c}\text { Edition } \\
2018-19\end{array}$ \\
\hline $\mathrm{A}$ & 3.50 & 3.60 & 0.51 & 0.59 & 4 & 4 \\
\hline $\mathrm{B}$ & 3.60 & 3.60 & 0.55 & 0.57 & 4 & 4 \\
\hline $\mathrm{C}$ & 2.90 & 3.00 & 1.01 & 0.98 & 4 & 4 \\
\hline $\mathrm{D}$ & 3.10 & 3.30 & 1.08 & 1.06 & 4 & 4 \\
\hline $\mathrm{E}$ & 3.50 & 3.60 & 0.73 & 0.66 & 4 & 4 \\
\hline $\mathrm{F}$ & 2.60 & 3.00 & 1.00 & 0.90 & 3 & 3 \\
\hline $\mathrm{G}$ & 1.90 & 2.20 & 0.92 & 1.03 & 1 & 3 \\
\hline $\mathrm{H}$ & 3.30 & 3.60 & 0.89 & 0.65 & 4 & 4 \\
\hline \hline
\end{tabular}

As you can see in Table 2, the mean of the 7 items is higher than in the last edition, and the standard deviations are globally lower, indicating a greater homogeneity in the responses. These results 
reinforce the positive trend of the average values. The mode remains stable for all items except for item G, that in the first edition was 1 (over 4) and in the third one reaches 3 (over 4), being the most relevant growth observed.

It is worth highlighting together the values observed in items $D$ and $E$, referring to how capable the participants feel -before and after the contest- of naming 3 female profiles in the field of technology. The differences in the average values and deviation are not notable between the evaluation of the first and third edition, but the upward trend is observed. This element will be analysed in detail when more data becomes available in future evaluations, as it represents a particularly significant factor in terms of the practical impact of the contest.

We would like to focus on items $F$ and $G$, referring to the perception of the students regarding the impact of their participation in the contest from a more emotional, affective and social perspective, also including observable attitudinal elements. In these cases, the mean goes from 2.6/4 to $3 / 4$ and from $1.9 / 4$ to 2.2 , respectively. The standard deviation decreases in the first case, going from 1 to 0.90 , and increases in the second case, going from 0.92 to 1.03 . However, and as indicated at the beginning of the analysis, the mode moves from $1 / 4$ to $3 / 4$ in the case of item $\mathrm{G}$.

Finally, item $\mathrm{H}$ obtains a higher average value and less deviation, thus reflecting greater conviction and consensus related to the statement "I would recommend my friends the participation in the contest."

As indicated in the presentation of the applied instruments, in this edition three new items were added. These items are related to the perception of the students regarding the learning of technological and transversal competences. Table 3 shows these items and the average scores collected for each case, as well as the standard deviation and the mode. Note that the degree scale was between 1 and 4 , being 1 "I haven't learned anything" and 4 "l've learned a lot".

Table 3. Assessment of the student body regarding the learning of technological and transversal competences.

\begin{tabular}{l|c|c|c}
\hline \hline $\begin{array}{c}\text { How much have you leaned during the } \\
\text { contest about the following aspects: }\end{array}$ & Mean & Standard Deviation & Mode \\
\hline A. Web design & 3.0 & 0.96 & 3 \\
\hline B. Video editing & 2.4 & 1.06 & 2 \\
\hline C. Female professionals in technology & 3.2 & 0.89 & 4 \\
\hline \hline
\end{tabular}

As we can see in Table 3, for items $A$ and $C$ the value of the mode is at the highest value obtained in each case and the deviation is not significantly high. Regarding item $B$, the mean is $2.4 / 4$ and the mode is 2 , being this element the one with the lower impact. However, it's worth to mention that the standard deviation is higher than 1.

Next, students were asked to indicate what they liked the most and least about their participation in the contest. Table 4 shows the most relevant responses and also reports their frequency between parenthesis.

Table 4. Students qualitative comments

\begin{tabular}{l|l}
\hline \hline \multicolumn{1}{c|}{ What I liked the most } & What I liked the least (things to improve) \\
\hline $\begin{array}{l}\text { - The topic and objective of the contest, as well as the developed tasks: } \\
\text { searching for women in technology, going deeply into the role of } \\
\text { women in technology and their work, thinking about the best format of } \\
\text { the website for getting the highest visibility. (26) }\end{array}$ & $\begin{array}{l}\text { - Technical aspects: web domain, video } \\
\text { editing, etc. (9) } \\
\text { - Evaluation of the final result to proclaim } \\
\text { the winning team (5) } \\
\text { - Everything related to the design and the development of the interviews: } \\
\text { knowing the selected candidates, their lives and achievements. (24) }\end{array}$ \\
- Technical competences: web design, video editing, etc. (19) & $\begin{array}{l}\text { Aspects related to task management, } \\
\text { difficulty of finding and contacting } \\
\text { - Temen. (3) }\end{array}$ \\
$\begin{array}{l}\text { (16) } \\
\text { - The impact of extracurricular learning. (15) }\end{array}$ & \\
- The exiting experience of participating in a contest (7) & \\
\hline \hline
\end{tabular}


Students report 107 elements that they liked the most from the contest. Those more frequent were the topic and objective of the contest, as well as its inherent tasks: searching for women in technology, going deeply into the role of women in technology and their work, etc. These elements account for the $24.3 \%$ of the gathered feedback. Most of the students also liked the design and development of the interviews. This item was not included in the previous one, as it computes for the $22.4 \%$. Technical competences (19 mentions), transversal competences (16 mentions) and the impact of extracurricular learning (15 mentions) were also very much valued. Particularly, these items generated more interest in this edition than in the previous one.

The students also reported elements they liked the least (19 comments) or aspects to improve (24 comments). The common elements were technical aspects, the verdict of the committee, or other aspects related to the organization or timing.

At the end of the questionnaire, students could add global comments. We registered 11 comments that highlighted the impact of the contests and give some ideas such as expanding the scope of the project to STEM (not only technology) or modifying its timing.

\section{CONCLUSIONS}

The evaluation carried out in the third edition of the contest Wisibilizalas, shares some elements, both in the case of teachers and students, with those collected in the evaluation of the first edition. Particularly, the intrinsic motivation and personal interest on the topic of the contest computes the $57 \%$ of the responses in the case of students and $100 \%$ in the case of teachers (adding in this case the explicit work of transversal competences related to gender, science, respect, etc.).

In this line, both the teaching staff and the students highlight, in general, the positive participation in the contest, that provided them with technological and transversal competences such as teamwork, or research skills. In both cases they agree that they would recommend their colleagues to participate in the contest.

Regarding the evolution of the impact of the activity in two of its editions, we would like to note the increase in the impact perceived by the participants (both teachers and students) at a cognitive level (technical and transversal skills) and at a socio-affective and emotional level. It's also worth to mention the expansion of the geographic scope of the contest to Latin America, becoming an international contest.

As a final discussion, this study has made it possible to evaluate the cross-sectional impact that an extracurricular activity has had on a pre-university audience. Through a contest aimed at mixed groups of Primary and Secondary school, it has been possible to break gender stereotypes associated with technological professions, give visibility to the role of women in this field, promote interest in careers technological skills and provide students with digital and transversal skills.

\section{ACKNOWLEDGEMENTS}

Authors acknowledge the financial support of the companies involved in the third edition of the contest: NAE Comunicacions S.L., SILK Aplicaciones S.L.U., CASIO España S.L., SERVIZURICH S.A. and Google's Women Techmakers program.

\section{REFERENCES}

[1] Ministerio de Educación y Formación Profesional, Igualdad en cifras, 2019. Retrieved from https://bit.ly/2sy8uXs.

[2] Al Now, Discriminating Systems. Gender, race and power in Al, 2019. Retrieved from https://bit.ly/2FX4FOv

[3] $\mathrm{MSCl}$, The tipping point - Women on boards and financial performance, 2016. Retrieved from https://bit.ly/2NBuSGE

[4] S. Cheryan, J.O. Siy, M. Vichayapai, B.J. Drury and S. Kim, "Do Female and Male Role Models Who Embody STEM Stereotypes Hinder Women's Anticipated Success in STEM?", in Social Psychological and Personality Science, 2011. Vol 2, Issue 6, pp. 656 - 664. 2011. 
[5] D. Cvencek, A.N. Meltzoff and A.G. Greenwald, "Math-Gender Stereotypes in Elementary School Children", in Child Dev, 2011. 82(3):766-79. 2011.

[6] J. Osborne, S. Simon and S. Collins, "Attitudes towards science: A review of the literature and its implications", in International Journal of Science Education, 2003. 25:9, 1049-1079. 2003.

[7] C.Corbett and C.Hill, Solving the equation. The variables for women's success in Engineering and Computing. Washington. American Association of University Women. 2015.

[8] C.A. Moss-Racusin, J.F. Dovidio, V.L. Brescoll, M.J. Graham and J. Handelsman, "Science faculty's subtle gender biases favor male students", in PNAS 2012. 109 (41) 16474-16479. 2012.

[9] R. A. Dore, K. M. Hoffman, A. S. Lillard and S. Trawalter, "Children's racial bias in perceptions of others' pain", in British Journal of Developmental Psychology, 2014. 32: 218-231. 2014.

[10] A. Freire, A. Ruiz-Garcia, and V. Moreno Oliver, "Wisibilizalas: Promoting the Role of Women in ICT among Secondary School Students". In Proc. of 1st International Conference on Gender Research, 2018. ICGR 2018. pp. 151-160. 2018. 